\title{
A systematic review to assess the effectiveness of technology-based interventions to address obesity in children
}

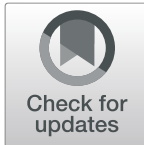

\author{
Megan McMullan', Rachel Millar ${ }^{1}$ and Jayne V. Woodside ${ }^{2^{*}}$
}

\begin{abstract}
Background: Childhood obesity is associated with a multitude of co-morbidities, including hypertension, hyperlipidaemia, cardiovascular disease and type 2 diabetes. Childhood obesity can also affect a young person's social, emotional and mental health if they encounter negative prejudice and social marginalisation. Given the prevalence of overweight and obese children globally, it is imperative that effective interventions are developed. Children are receptive to information conveyed via digital means, therefore, the use of technology may play a crucial role in interventions to reduce childhood obesity. This systematic review aimed to review and critically appraise the literature published to date in relation to the effectiveness of technology-based interventions, employed as secondary prevention, in addressing childhood obesity.
\end{abstract}

Methods: An electronic search strategy was undertaken in Medline and Embase, covering publications up to and including 12th July 2018. Randomised controlled trials assessing the effectiveness of technology-based interventions on weight-related outcomes in children, aged 8 to 18, published only in the English language, were included.

Results: From an initial search total of 1012 studies, 11 met the inclusion criteria. They were assessed for methodological quality using the Cochrane Risk of Bias Tool for Randomised Controlled Trials and were analysed using a narrative approach. The findings of this review showed a limited potential of technology-based interventions, employed as secondary prevention, to address childhood obesity. Of the eleven studies reviewed, three (27\%) showed a positive relationship between technology-based interventions and weight-related outcomes in overweight or obese children.

Conclusions: This review suggests that technology-based interventions, primarily active video games, as well as internet or web-based interventions and mobile phone communications, may, with further research, have the potential to impact positively on weight-related outcomes. It is difficult to determine the degree of efficacy of these technology-based interventions, as only two databases were searched, selecting only English language articles. Moreover, the included studies demonstrated a lack of high-quality evidence. The lack and heterogeneity of studies with technology-based interventions is a further limitation.

Keywords: Technology, Intervention, Obesity, Children, Web-based, Active video game, Exer-gaming, Internet

\footnotetext{
* Correspondence: j.woodside@qub.ac.uk

${ }^{2}$ Institute for Global Food Security (Centre for Public Health), Grosvenor Road, Belfast BT12 6BJ, UK

Full list of author information is available at the end of the article
}

C C The Author(s). 2020 Open Access This article is licensed under a Creative Commons Attribution 4.0 International License, which permits use, sharing, adaptation, distribution and reproduction in any medium or format, as long as you give appropriate credit to the original author(s) and the source, provide a link to the Creative Commons licence, and indicate if changes were made. The images or other third party material in this article are included in the article's Creative Commons licence, unless indicated otherwise in a credit line to the material. If material is not included in the article's Creative Commons licence and your intended use is not permitted by statutory regulation or exceeds the permitted use, you will need to obtain permission directly from the copyright holder. To view a copy of this licence, visit http://creativecommons.org/licenses/by/4.0/ The Creative Commons Public Domain Dedication waiver (http://creativecommons.org/publicdomain/zero/1.0/) applies to the data made available in this article, unless otherwise stated in a credit line to the data. 


\section{Background}

Overweight and obesity are defined as conditions of abnormal or excessive body fat accumulation that exceeds healthy limits, presenting a risk to health [1]. Overweight and obesity is a worldwide epidemic among children and adolescents; in 2016 over 340 million children and adolescents aged 5-19 were overweight or obese [2]. Global age-standardised prevalence of obesity in girls demonstrated an increase from $0.7 \%$ in 1975 to $5.6 \%$ in 2016 and from $0.9 \%$ in 1975 to $7 \cdot 8 \%$ in 2016 in boys [3]. Despite evidence of recent decline in childhood obesity rates in the USA [4], more than 12 million American children in the USA are obese - one in every six [5].

\section{Interpretation}

The rising trends in children's and adolescents' BMI have plateaued in many high-income countries, albeit at high levels, but have accelerated in parts of Asia, with trends no longer correlated with those of adults.

Due to the prevalence of overweight and obese children globally, effective interventions are urgently required.

Childhood obesity is associated with a multitude of co-morbidities, including cardiovascular disease, type 2 diabetes and orthopaedic problems [6]. Childhood obesity may also affect the young person's social and emotional health, as they can encounter negative prejudice and social marginalization [7]. This adverse stereotyping contributes to poor mental health, which can affect academic performance, resulting in restricted future employment opportunities [6].

Technology in the twenty-first century has become an integral part of everyday life for children. They live in a media-saturated environment, with $94 \%$ of 8 to 11 year olds and $99 \%$ of 12 to 15 year olds in the UK using a variety of technological devices [8]. The ensuing sedentary lifestyle can perhaps best be addressed by using the screen, their main source of entertainment and communication, as a medium to educate and motivate the child to adopt a healthier lifestyle.

Non-technological weight management interventions are not always accessible to children due to prohibitive cost, transport difficulties and lack of provision [9]. With up to $80 \%$ of children between 12 and 17 reluctant to engage in any form of organized sporting activity, there is a need for other innovative interventions [10].

To date, technology-based interventions, such as internet- and social media-based weight management programmes, smartphone apps and active video games have been developed to educate overweight and obese children [11-13]. These interventions are readily accessible, inexpensive and time-saving, allowing the child to engage independently from home with anonymity.
An et al. [14] conducted a systematic review of randomised controlled trials (RCTs) examining the effect of web-based weight management programs for children and adolescents. The authors found that six of eight studies confirmed that internet-based interventions, either alone or in combination with other behavioural interventions, had significant beneficial effects on reported outcomes. Two of three studies that compared internetbased interventions to a non-intervention group established that the BMI in internet-based intervention groups was significantly reduced. The time scale of these effective interventions varied, all studies covered a minimum period of twelve weeks and two continued for 2 years. The review focused on internet-based interventions only, rather than the full range of technologybased interventions employed as secondary prevention to address childhood obesity.

As children spend a significant amount of time on their technological devices, playing active video games or exergaming allows them to become more active and expend more energy [15]. Exergaming is using video games as a form of exercise. A systematic review has indicated that exergames generate moderate intensity levels of physical activity as well as being enjoyable. A 4 month RCT reported on the positive effects of active video games on weight and physical activity (PA) in a cohort of overweight and obese children [16].

To date, most research has focused on the effectiveness of technology-based interventions as primary prevention of childhood obesity. For example, Chen at al [17]. assessed the efficacy of technology-based interventions for obesity prevention in adolescents. There is a lack of knowledge on the impact of a full range of technology-based interventions on weight management in already overweight and obese children. The aim of this review was, therefore, to investigate the effectiveness of technology-based interventions, employed as secondary prevention, in addressing childhood obesity.

\section{Methods}

This systematic review was conducted in accordance with the PRISMA (Preferred Reporting Items for Systematic Reviews and Meta-Analysis) guidelines [18]. There was no published review protocol. Eligibility criteria were:participants aged from 8 to 18 years, all or some of whom had to be overweight or obese. Three established definitions for overweight and obesity were accepted [19-21]. Technology-based interventions, such as social media, mobile phones, websites and active video games addressing childhood obesity, occurring in all settings and with the aim of decreasing BMI and other weight related outcomes, were included. Intervention period was minimum 2 weeks. The control was non-technology-based interventions or the stated technology-based interventions compared with each 
other. The primary outcome was BMI and secondary outcomes were other weight related outcomes, including weight, BMI percentile, BMI z-score, percentage body fat (\% BF), waist circumference (WC) and waist to hip ratio (WHR). Only RCTs, including parallel group, cluster randomised and randomised cross-over trials, were allowed. Excluded were participants outside the specified age, those with a medical condition impacting on diet, weight or ability to exercise and studies comprising only of normal or underweight children. Studies examining technology-based intervention as part of a multicomponent intervention and studies published in a language other than English were excluded.

A search strategy was undertaken to identify relevant studies for inclusion. The search was last updated on 13th July 2018, in Medline and Embase.

Searches employed the AND combination of two main concepts: Obesity and Technology. Key words, including synonyms, closely related words and spelling variations, for each of the two concepts were combined using the operator 'OR'. The searches were restricted to RCTs, English language and human only studies. Figure S1 demonstrates the search strategy for Embase. (See Additional file 1).

Duplicate studies were removed, as titles of studies considered irrelevant. Abstracts of potentially relevant titles were screened for inclusion, followed by full texts, and full texts were reviewed by a second reviewed for consensus (RM), with divergence resolved through discussion. Reference lists of included articles were also reviewed for eligibility.

The following data were extracted: authors and year of publication, study design, study location, number of participants in analysis, gender, age and characteristics of participants, study retention rate, the intervention and control, intervention duration and intensity, outcomes measured, follow up details and key findings.

Methodological quality was evaluated using the Cochrane Risk of Bias Tool for Randomised Controlled Trials [22], with results translated to the Agency for Healthcare Research and Quality (AHRQ) standard of 'good', 'fair', and 'poor' quality, using established conversion thresholds [22]. RevMan was used to produce a 'Risk of bias table', a 'Risk of bias graph' and a 'Risk of bias summary'.

A narrative approach to data synthesis was used, rather than meta-analysis, primarily due to the heterogeneous nature of the included studies.

\section{Results}

One thousand twelvearticles were obtained from Medline $(n=204)$ and Embase $(n=808)$ and were screened to remove duplicates. Titles and abstracts of the remaining 875 unique articles were screened and 851 studies rejected. Two reviewers independently examined the full text of the 24 remaining articles for inclusion. Eight articles were excluded due to participants being outside the specified age range; two others because they described primary prevention interventions; a further two due to insufficient participant information and one because the technology-based intervention was part of a multicomponent intervention. Therefore a total of 11 studies were considered suitable for inclusion. No further articles were retrieved from the bibliography search. Figure S2 demonstrates the study selection process (See Additional file 2).

An overview of study characteristics extracted for this review is presented in Table 1. Year of publication ranged from 2006 [23] to 2017 [24]. Studies were all RCTs, three of which were cluster RCTs, where two randomised schools $[25,26]$ and one randomised a mixture of schools and YMCAs [16]. The studies were carried out in a range of countries, with the majority taking place in the USA $(n=6)[9,16,23,24,27,28]$ and others in New Zealand $(n=2)[29,30]$, Canada $(n=1)$ [31], Malaysia $(n=1)$ [26] and the Netherlands $(n=1)$ [25]. Study retention rates ranged from $70.2 \%$ [23] to $100 \%$ $[26,30]$.

The total number of participants analysed varied from 26 [31] to 742 [25], with an age range from 10 years [16] to 16 years [24]. The majority of studies included both genders, with a small number of studies conducted among females only $(\mathrm{n}=2)[23,24]$. Two studies focused exclusively on participants of one particular ethnicity; one focused on Chinese-American adolescents [27], while the other focused on African-American girls [23]. Two studies did not specify ethnicity $[25,31]$, while the remaining seven studies focused on children from a variety of ethnic origins $[9,16,24,26,28-30]$.

All studies focused on technology-based interventions as secondary prevention, since participants were overweight or obese prior to commencement of study. However, two studies also included participants who were normal weight and presented this data separately. In this case, the intervention also served as primary prevention $[25,27]$.

One study included participants who engaged in binge eating or overeating behaviours [9]. Two studies had a family component, one of which provided three 15-min internet sessions for the parents so that they might acquire the skills to support their children in leading a healthy lifestyle [27]. The other study required the adolescents to participate in the study with a parent [23].

There was some heterogeneity in how weight categories were defined. Seven studies used the CDC definition [9, $16,23,24,27,28,31$ ] and two studies used the IOTF definition to explain the terms normal, overweight and obese $[25,30]$. Two studies did not employ an established definition; one required participants to have a BMI $>25 \mathrm{~kg} / \mathrm{m}^{2}$ 


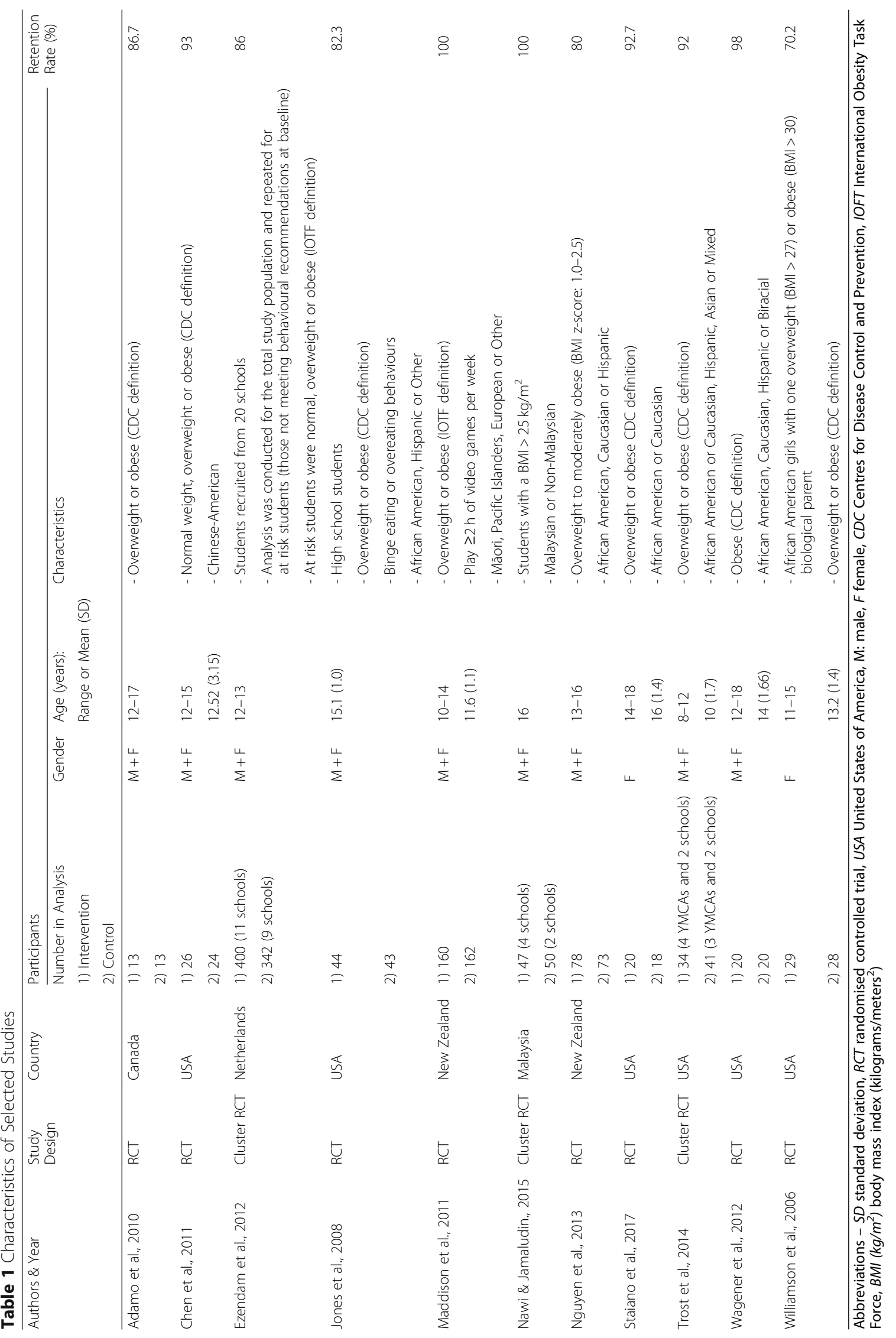


[26], while the other classed its participants as overweight or obese with a BMI z-score between 1.0 and 2.5 [29]

Details of the intervention and control groups, outcomes, follow-up time points and key findings, including the effectiveness of interventions on BMI and other weight-related outcomes, for each included study were noted. The mean difference of weight-related outcomes between intervention and control groups was also calculated.

Technology-based interventions were sub-divided into three main categories; active video games or exergaming, internet or web-based interventions and mobile phone communications. Intervention duration ranged from 8 weeks [27] to 2 years [23, 29]. Intervention intensity was reported in all but two studies $[16,26]$ and was highly heterogeneous. Follow-up time points varied across studies from between 2 months [27, 29] and 24 months $[23,25,29]$. Four studies compared a technology-based intervention to a nil intervention control group [9, 24, 25, 28]; four studies compared a technology-based intervention to a non-technology-based intervention, and these included stationary cycling to music [31], written pamphlets [26] and lifestyle programmes [16, 29]. Three studies compared the effectiveness between different technologybased interventions, however, the intervention of interest had an interactive or tailored component compared to the passive or sedentary technology-based control intervention $[23,27,30]$. The study outcomes varied depending on the aims of the studies but they all included a BMI outcome, given as either BMI, BMI z-score or BMI percentile. Further common outcomes were other anthropometric, dietary and PA measurements.

\section{Active video game interventions}

Five studies explored the effectiveness of active video gaming or exergaming [16, 24, 28, 30, 31] (Table 2).

Adamo et al. [31] investigated the effectiveness of an interactive video game which involved stationary cycling, known as 'GameBike', compared to stationary cycling to music. The study focused on exercise adherence, energy expenditure, aerobic fitness, body composition, and cardiovascular disease risk markers in overweight and obese adolescents. The author found that the music group had significantly better adherence and expended more energy than the 'GameBike' group. There were no other notable differences between the two groups. Within both groups, statistically significant findings included a reduction in peak heart rate (HR) at peak workload, an improvement in peak workload and a reduction in time to exhaustion from pre to post intervention. There were no statistically significant between or within group differences for BMI.

Furthermore, in the second study, Maddison et al. [30] explored the effect of active video games on weight, body composition, PA and physical fitness compared to the effect of sedentary video games. This study established that children in the active video games group had significantly decreased their BMI, BMI z-score, \% BF and body weight compared to the children in the sedentary video games group.

The objective of the third study by Staiano et al. [24] was to examine the effect of exergaming on adolescent girls' body composition and their cardiovascular risk factors compared to a control group who adhered to their normal PA level. No statistically significant differences in body composition or cardiovascular risk factors between the two groups were found at follow-up.

The aim of the fourth study by Trost et al. [16] was to evaluate the effects of active video gaming on PA and weight loss in children participating in a communitybased weight management programme. Statistically significant increases in PA were confirmed in the active video gaming group compared to the control group. The control group participated only in the programme and had no access to active video gaming. Both groups had statistically significant reductions in percentage of children overweight and BMI z-scores, however, the active gaming group demonstrated statistically significantly greater reductions.

Finally, Wagner et al. [28] investigated the impact of dance-based exergaming on obese adolescents' perceived ability to exercise, their psychological adjustment and their BMI compared to a wait-list control group. It was noted that there was a statistically significant increase in self-reported perceived ability to exercise compared to the control group. However, no statistically significant differences were found in BMI z-score within or between the two groups.

In conclusion, two out of these five studies demonstrated a statistically significant mean difference for the intervention compared to the control for all or some of their weight-related outcomes; Maddison et al. [30] found beneficial results for four weight-related outcomes. BMI, BMI z score, body weight and \% BF, with a statistically significant mean difference of $-0.24,-0.06$, -0.72 and -0.83 respectively when compared to control group, with $P$-values of $0.02,0.03,0.02$ and 0.02 . Trost et al. [16] found a statistically significant mean difference of -0.16 for BMI z-score when compared to the control group with a P-value of $<0.001$. The remaining findings were not statistically significant on between and within group analyses and displayed a degree of heterogeneity in estimates in terms of trend of direction.

\section{Internet-based interventions}

Five studies examined the effect of web-based or internet interventions (Table 3) [9, 23, 25-27].

Chen et al. [27] aimed to examine the efficacy of a theory-driven, family-based online programme to promote healthy lifestyles and weights in Chinese-American adolescents. This was compared to guidance given on a 


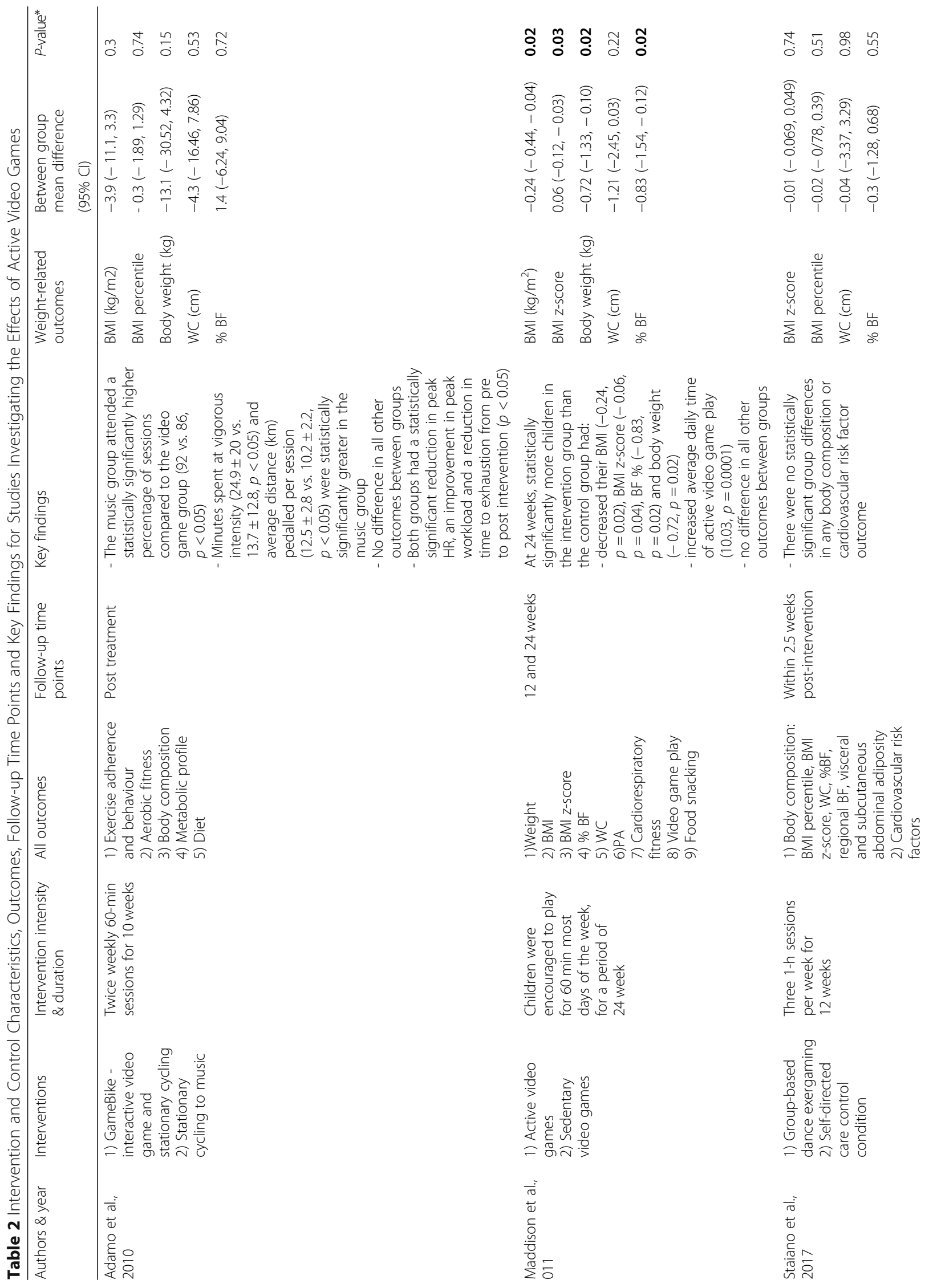




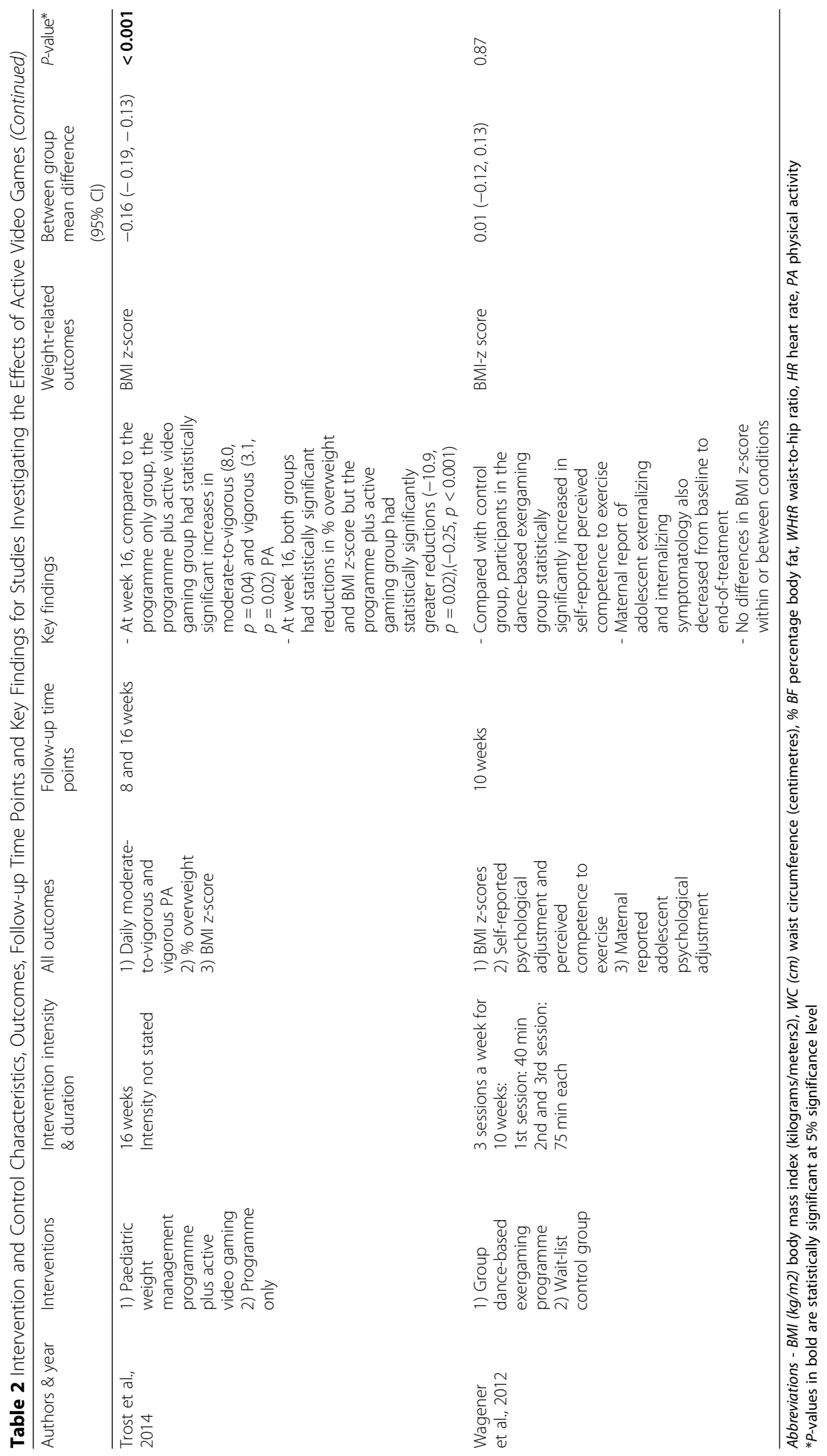




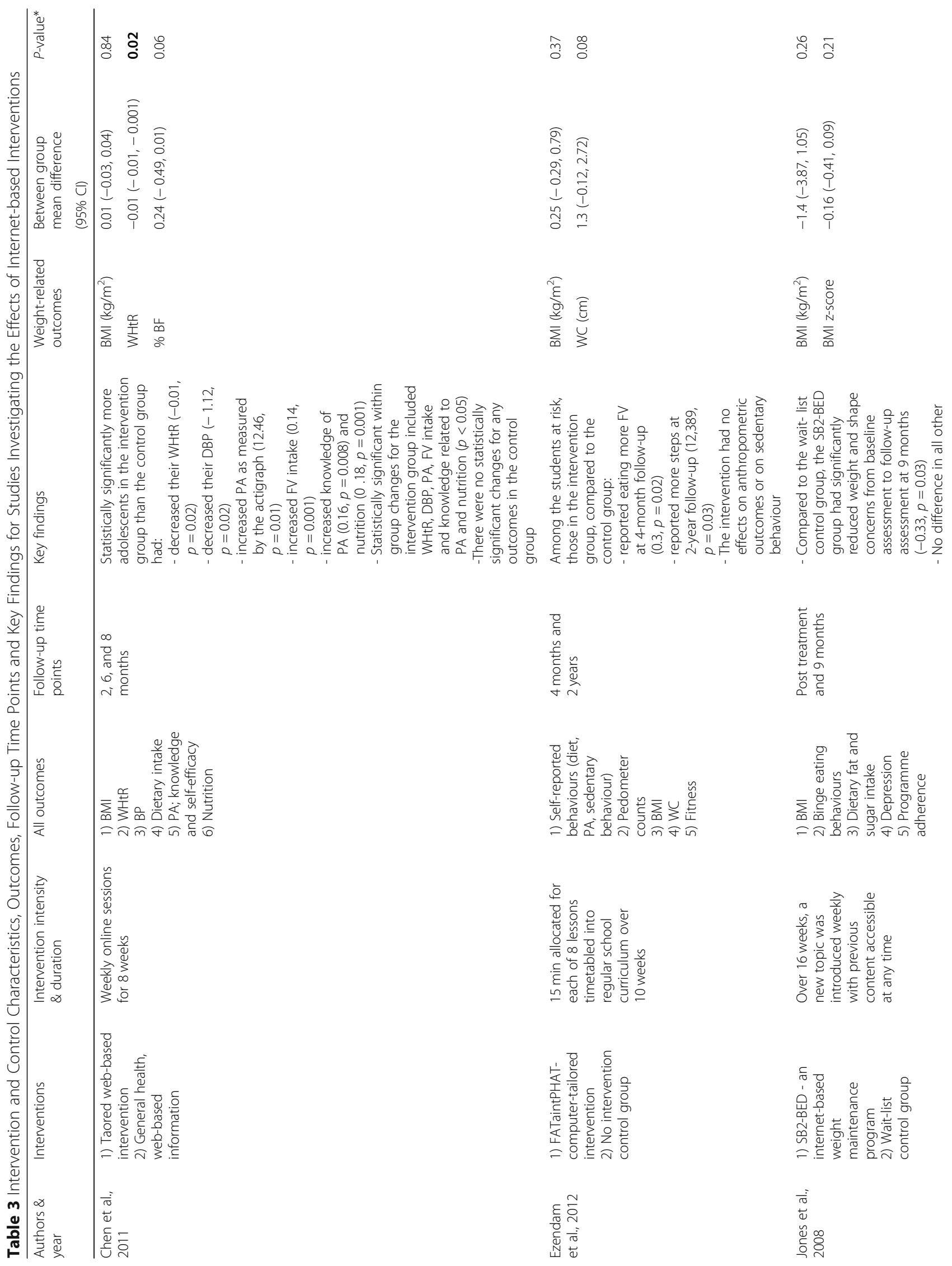




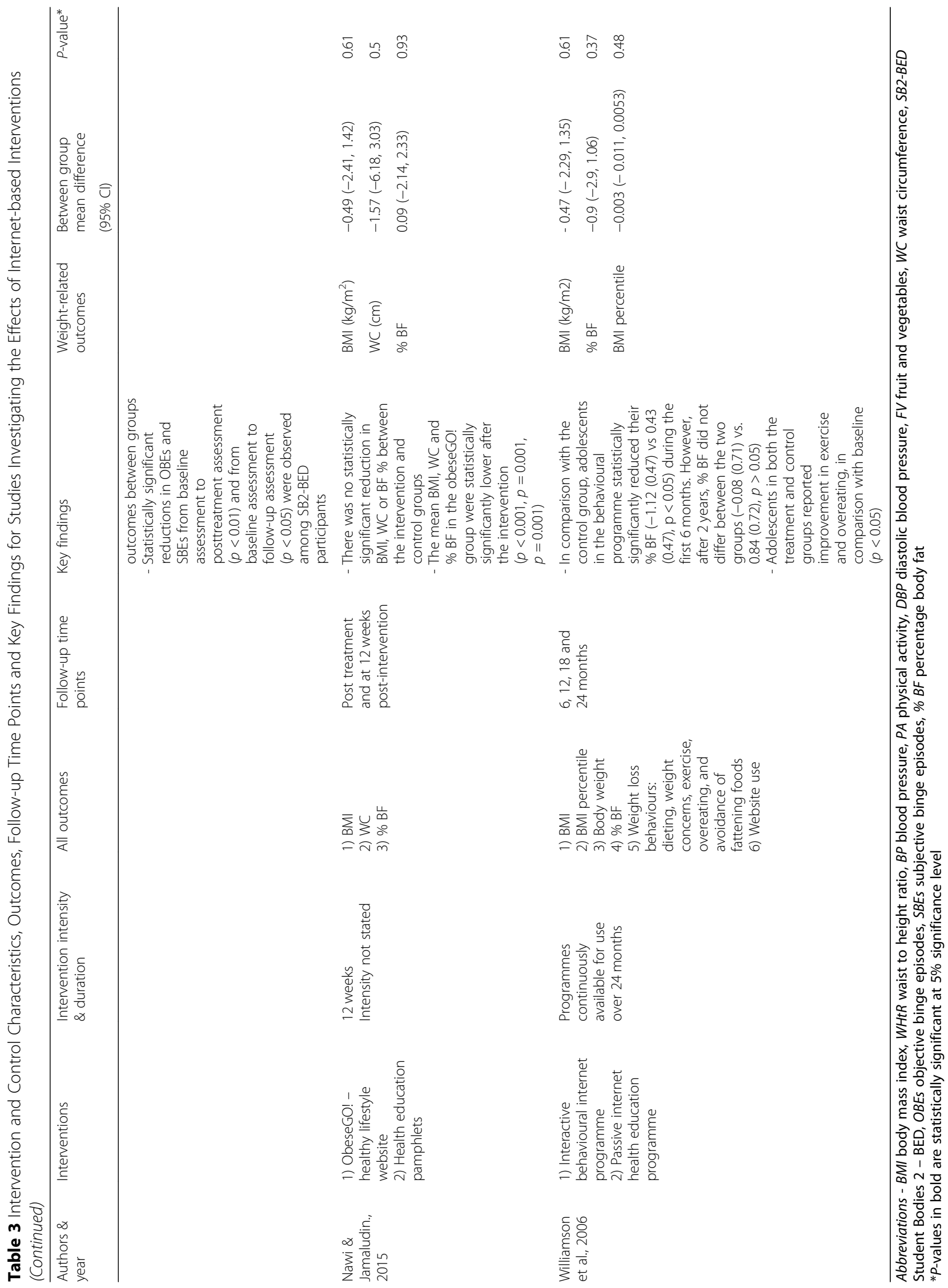


general health website. Outcomes included BMI, Waistto-hip ratio (WHtR), diet, PA and knowledge about PA and nutrition. Chen et al. [27] found that adolescents in the intervention group, compared to the control group, had statistically significantly decreased their WHR and their diastolic blood pressure (DBP) while statistically significantly increasing their PA, improving their diet and increasing their knowledge in regard to PA and nutrition. Statistically significant within group changes for the intervention group included WHtR, DBP, PA, fruit and vegetable intake and knowledge related to PA and nutrition. There were no statistically significant within-group changes for any outcomes within the control group.

Similarly, Ezendam et al. [25] conducted a study to evaluate the short- and long-term results of FATaintPHAT, a web-based computer-tailored intervention which aimed to increase PA, decrease sedentary behaviour and promote healthy eating in adolescents. The control group was a nil intervention group. Outcomes included self-reported behaviours in terms of diet, PA and sedentary behaviour, step count, fitness measured by a shuttle run test, as well as anthropometric measures. Analysis for this study was conducted for the total study population and repeated for all at risk students, namely those who did not meet behavioural recommendations at baseline. This study found that, for at risk students, the intervention had no statistically significant effect on anthropometric outcomes or on sedentary behaviour but did show a statistically significant increase in fruit and vegetable consumption at 4 month follow-up and increased steps at 2 year follow up. For the total study population, FATaintPHAT had no statistically significant effect on BMI, WC or percentage of overweight or obese students. However, at 4 month follow-up, the intervention group was less likely to report drinking more than $400 \mathrm{ml}$ of sugar sweetened beverages per day compared to the control group. At 2 year follow-up, this difference was not statistically significant.

Jones et al. [9] examined the effect of an internetfacilitated intervention for weight maintenance and binge eating in adolescents. The control was a wait-list control group, and outcomes included BMI, binge eating behaviours, fat and sugar intake, depression and programme adherence. This study reported no statistically significant differences in outcomes between groups. The only within group statistically significant finding in the intervention group was a reduction in objective and subjective binge episodes from baseline assessment to post-treatment and follow-up assessment.

A further web-based RCT by Nawi and Jamaludin [26] attempted to determine the effectiveness of an internetbased intervention (obeseGO!) to address obesity among adolescents in Kuala Lumpur compared to a control group who were provided with written health education pamphlets. Outcomes measured were anthropometric measures; specifically, BMI, WC and \% BF. This study found no statistically significant reduction in any outcomes between groups. However, on within-group analyses, mean BMI, WC and \% BF in the obeseGO! group were statistically significantly lower after the intervention.

Finally, Williamson et al. [23] conducted a study to test the efficacy of an internet-based lifestyle behaviour modification programme for African-American girls over a 2 year period. The control group was a passive internet health education programme. Outcomes measured were anthropometric measures, weight loss behaviours and website use. At the 6 month follow-up, participants in the intervention group in comparison to the control group had statistically significantly reduced their \% BF, however, this difference was not sustained and at the end of the 24 month intervention period, there was no difference in \% BF between the two groups. Adolescents in both groups reported a statistically significant improvement in exercise and a reduction in overeating, in comparison with baseline.

To summarise, one study out of the five had a statistically mean difference for the intervention compared to the control for one of its weight-related outcomes; Chen et al. [27] found a small but statistically significant mean decrease in WHtR (0.01) compared to the control group with a $P$-value of 0.02 . The remaining findings were not statistically significant when between group analyses were conducted and, as before, displayed a degree of heterogeneity in estimates in terms of trend of direction.

\section{Mobile phone communications}

The third category of technology-based interventions, mobile phone communications, was explored in a single study by Nguyen et al. [29], where the effect of supplementary therapeutic contact as an additional support to a community-based weight-management programme for overweight and obese adolescents was examined (Table 4). Additional therapeutic contact took the form of telephone coaching, SMS or email communications. The control group was the weight-management programme alone. Outcomes measured were anthropometric measures, blood pressure, metabolic profile and self-reported psychosocial and lifestyle changes. Both groups demonstrated statistically significant reductions in BMI z-scores and WHtR as well as improvements in metabolic and psychosocial profiles. The study found that this technology-based intervention had no statistically significant impact on body weight, BMI, BMI zscore, WC and WHtR compared to the control group.

In terms of statistically significant findings, active video gaming was demonstrated to have had a positive impact on weight outcomes in $40 \%$ of studies $(2 / 5)$. However, it is important to note that, within this review, five out of eleven studies focused on the use of active 
Table 4 Intervention and Control Characteristics, Outcomes, Follow-up Time Points and Key Findings for a Single Study Investigating the Effects of Mobile Phone-based Communications

\begin{tabular}{|c|c|c|c|c|c|c|c|c|}
\hline $\begin{array}{l}\text { Authors } \\
\text { \& year }\end{array}$ & Interventions & $\begin{array}{l}\text { Intervention } \\
\text { intensity } \\
\text { \& duration }\end{array}$ & Outcomes & $\begin{array}{l}\text { Follow-up } \\
\text { time points }\end{array}$ & Key findings & $\begin{array}{l}\text { Weight-related } \\
\text { outcomes }\end{array}$ & Mean difference & $P$-value* \\
\hline \multirow{5}{*}{$\begin{array}{l}\text { Nguyen } \\
\text { et al., } 2013\end{array}$} & \multirow{5}{*}{$\begin{array}{l}\text { 1) Behavioural } \\
\text { lifestyle } \\
\text { programme } \\
\text { plus: } \\
\text { telephone/ } \\
\text { SMS/email } \\
\text { 2) Programme } \\
\text { only }\end{array}$} & \multirow{5}{*}{$\begin{array}{l}2 \text { years } \\
\text { During Phase } 2 \\
\text { ( } 22 \text { months) } \\
\text { adolescents } \\
\text { received } 14 \\
\text { telephone } \\
\text { coaching } \\
\text { sessions and } \\
32 \text { SMS +/ } \\
\text { emails }\end{array}$} & \multirow{5}{*}{$\begin{array}{l}\text { 1) Weight } \\
\text { 2) BMI } \\
\text { 3) BMI z-score } \\
\text { 4) WC } \\
\text { 5) WHtR } \\
\text { 6) SBP \& DBP } \\
\text { 7) Metabolic } \\
\text { profile } \\
\text { 8) Self-reported } \\
\text { psychosocial } \\
\text { and lifestyle } \\
\text { changes }\end{array}$} & \multirow{5}{*}{$\begin{array}{l}2 \text { months } \\
\text { (end of } \\
\text { Phase 1) } \\
12 \text { months } \\
24 \text { months } \\
\text { (end of } \\
\text { Phase 2) }\end{array}$} & \multirow{5}{*}{$\begin{array}{l}\text { - In both arms the } \\
\text { programme produced } \\
\text { statistically significant } \\
\text { reductions in BMl } \\
\text { z-score, WHtR and } \\
\text { several metabolic } \\
\text { and psychosocial } \\
\text { improvements } \\
\text { - Compared to the } \\
\text { programme alone, } \\
\text { the additional } \\
\text { communication } \\
\text { had no statistically } \\
\text { significant impact on } \\
\text { outcomes }\end{array}$} & Body weight (kg) & $-2.1(-7.14,2.94)$ & 0.42 \\
\hline & & & & & & $\mathrm{BMI}(\mathrm{kg} / \mathrm{m} 2)$ & $-1.0(-2.45,0.45)$ & 0.18 \\
\hline & & & & & & BMI z-score & $-1.0(-0.24,0.04)$ & 0.18 \\
\hline & & & & & & $W C(\mathrm{~cm})$ & $-0.5(-4.36,3.36)$ & 0.18 \\
\hline & & & & & & WHtR & $0.00(-0.02,0.02)$ & 1 \\
\hline
\end{tabular}

Abbreviations - SMS short message service, $B M I$ body mass index, WC waist circumference, WHtR waist to height ratio, SBP systolic blood pressure, $D B P$ diastolic blood pressure

${ }^{*} P$-values in bold are statistically significant at $5 \%$ significance level

video games, while only one study explored mobile phone-based interventions, and this simple disparity in number of studies conducted to date may partly account for this outcome.

\section{Quality assessment}

When methodological quality was evaluated [22], all studies fell into the category of poor quality. Figure S3 is a pictorial risk of bias summary for each of the studies (See Additional file 3). Such low quality, and challenges in judging the presence of selection, performance, attrition and other bias in the included studies renders the evidence less trustworthy and creates a challenge for making reliable recommendations for future practice. The high risk of performance bias found in three studies is concerning particularly in the lack of blinding of participants and personnel.

\section{Discussion}

The aim of this systematic review was to assess the effectiveness of technology-based interventions, namely active video gaming, internet or web-based interventions and mobile phone communications, employed as secondary prevention, to address childhood obesity. However to combat obesity successfully, multicomponent interventions considering both diet and physical activity are likely to be required.

The review assessed the effect of these interventions on weight-related outcomes including weight, BMI percentile, BMI z-score, \% BF, WC and WHR, compared to a control group, which had been assigned either nil intervention, a non-technology-based intervention or a similar technologybased intervention but with a more passive or sedentary element. The review allowed comparison between the three types of technology-based interventions by analysing the proportion of studies demonstrating positive effects on weight-related outcomes.

Of the eleven studies reviewed, three showed a positive relationship between technology-based interventions and weight-related outcomes in overweight or obese children. The findings of this review overall showed a weak evidence base regarding the role of technology-based interventions, employed as secondary prevention, to address childhood obesity.

Of the five studies, which explored the effect of active video gaming or exergaming, two demonstrated a statistically significant mean difference for the intervention compared to the control for all or some of the weight-related outcomes. Maddison et al. [30] found statistically significant beneficial results for BMI, BMI z-score, body weight and \% $\mathrm{BF}$ when comparing the effects of active video games to sedentary video games. Trost et al. [16] compared a paediatric weight management programme in conjunction with active video gaming to the weight management programme alone and found a statistically significant mean difference for BMI z-score between and within groups.

In terms of studies which explored the effect of internet or web-based interventions, one out of five studies, which was by Chen et al. [27] found a small but statistically significant mean decrease in WHtR compared to the control group. There was also a statistically significant reduction of WHtR within the intervention group.

A single study by Nguyen et al. [29], which compared the effect of a behavioural lifestyle programme, supported by telephone and text messages or email, with the lifestyle programme alone found no statistically 
significant between group differences. However, within both groups, there were statistically significant reductions in BMI z-score and WHtR.

Active video games and internet-based interventions had some statistically significant effects on weight-related outcomes compared to control groups, while mobile phone communications had no effect. However, it is important to note that only one study explored mobile phone-based interventions. This disparity may partially explain the outcomes. While internet-based interventions were examined in a similar number of studies, they demonstrated a lower proportion of positive effects. The review suggests that active video games were most effective in terms of demonstrating positive effects on weightrelated outcomes. However, in the absence of a direct comparison between the various types of intervention it is difficult to ascertain the efficacy of one over the other.

Statistically significant results were noted with interventions of longer duration for active video games. However, no association between longer duration and statistically significant positive outcomes was noted for internet or web-based interventions.

The findings of this systematic review produced results which were consistent with other, similar systematic reviews, of which there is a limited number. Previous systematic reviews have demonstrated the potential of technology-based interventions, such as internet-based weight management programmes, mobile phones and active video games, to educate and help overweight and obese children. An et al. [14] examined RCTs assessing the effect of web-based weight management programmes alone for children and adolescents. The review found that, in two out of three studies, where internet-based interventions were compared with a control group, the BMI in the internet-based intervention groups was statistically significantly reduced. A further systematic review by Chen et al. [32] confirmed the potential of technology-based interventions, similar to those assessed in this review, for reducing the risk of obesity in adolescents. The current systematic review addressed a specific gap in knowledge in that it focused on the role of various, current technology-based interventions, employed as secondary prevention as opposed to primary, to address childhood obesity.

Findings from this review, which demonstrate the potential of technology-based interventions in improving weight related outcomes in a population of overweight or obese children, are consistent with previous literature. This is the first review to search the literature to identify all studies, which explore the effectiveness of technology-based interventions, employed as secondary prevention, to address childhood obesity. Furthermore, this review identified active video games as potentially the most effective technology-based intervention in addressing obesity in children.

\section{Strengths and limitations}

In terms of study strengths, the majority of studies used and described method of randomisation appropriately, leading to a reduced likelihood of selection bias. In addition, there were low levels of selective reporting, leading to a reduced likelihood of reporting bias. All weight-related outcomes in the included studies were measured objectively, reducing the likelihood of inaccuracy.

Study weakness included a lack of methodological clarity. This was partly due to the lack of blinding of participants, which would have proved difficult to carry out. All included studies proved to be of poor quality when AHRQ standards were applied, resulting in a potential loss of confidence in the study outcomes. The eleven studies were conducted by different investigators and different institutions in various locations worldwide; study variance must, therefore, be taken into consideration. Study participants varied in terms of gender, age, ethnicity and weight status. Studies differed in terms of interventions investigated, aims, follow-up times, attrition rates and outcomes measured. This heterogeneity among included studies restricts the ability to make direct comparisons and draw reliable conclusions.

Strengths of the review included clarity and robustness of its methods, which were reproducible and transparent. A methodical approach was used to determine the final eleven studies, allowing potential for repeatability. A comprehensive search strategy was employed and appropriate eligibility criteria applied to the potentially relevant studies. Reasons for exclusion were documented to ensure transparency. A second reviewer (RM) independently screened the full text articles to ensure consensus on study selection. Furthermore, the bibliographies of included articles were checked to identify other articles not listed in the two databases. The methodological quality of each study was considered when drawing conclusions from this review. Justification for not carrying out a meta-analysis was given, with an appropriate narrative approach adopted.

Two large, relevant databases were searched for the review and all reference lists were hand-searched. However, it may be that relevant studies were missed, which might impact on conclusions and recommendations. The search was limited to English language, which may introduce a language bias. Moreover, the initial screening of study titles and abstracts was conducted by one author only which in turn may be regarded as a limitation.

\section{Conclusions}

The review suggests that technology-based interventions may be effective in terms of demonstrating positive effects on weight-related outcomes, and that the effectiveness may depend on the type of technology used. 
However, without a direct comparison between the various types of intervention, it is difficult to draw a firm conclusion. Moreover, it was difficult to identify common characteristics in papers with similar findings and, due to the heterogeneity and poor quality of included studies, caution should be used when interpreting the results in relation to the review question and when translating to professional practice.

The review highlights that there is some potential of technology-based interventions, but also the need for further investigation and careful evaluation. Future research needs to address the aforementioned limitations of currently published findings. With only one included study assessing the effectiveness of mobile phone communications, more studies should be initiated in this area. Further research might establish if the setting where the intervention takes place has an impact on the efficacy of the intervention. No guidelines currently exist regarding the optimal intervention duration period, and more research needs to be undertaken to determine this. Longer intervention duration periods and associated follow-up periods would allow for assessment of longterm effects and their sustainability. In the future, consideration should also be given to the significance of the age of participants as children and adolescents might differ in their attitudes and response to the various technology-based interventions.

\section{Supplementary information}

Supplementary information accompanies this paper at https://doi.org/10 1186/s12887-020-02081-1.

Additional file 1: Figure S1. Search strategy used in Embase.

Additional file 2: Figure S2. Flow diagram summarising the study selection process.

Additional file 3: Figure S3. Risk of Bias Summary: Judgements on each risk of bias item for included.

\section{Abbreviations}

RCTs: randomised controlled trials; BMI: body mass index; PRISMA: Preferred Reporting Items for Systematic Reviews and Meta-Analysis; BF: body fat; WC: waist circumference; WHR: waist to hip ratio; CDC: Centres for Disease Control and Prevention; IOFT: International Obesity Task Force; PA: physical activity; DBP: diastolic blood pressure; SMS: short message service;

AHRQ: agency for healthcare research and quality

\section{Acknowledgements}

I would like to thank Richard Fallis (Queen's University Belfast Librarian) for his assistance in developing the search strategy.

\section{Authors' contributions}

MMCM and JW developed the research question and methodology. MMcM developed and conducted the search and screened titles, abstracts and full text articles. RM independently screened full text articles. MMcM carried out data extraction, data synthesis, quality assessment and wrote the initial manuscript. JW provided expert advice throughout and contributed to the final manuscript. All authors read and approved the final manuscript.
Funding

Completed as a postgraduate thesis funded by Student Finance, Northern Ireland.

Availability of data and materials

Data sharing is not applicable to this article as no datasets were generated or analysed during the current study.

Ethics approval and consent to participate

Not applicable.

\section{Consent for publication}

Not applicable.

\section{Competing interests}

The authors declare that they have no competing interests.

\section{Author details}

'School of Medicine, Dentistry and Biomedical Sciences, Queen's University Belfast, University Road, Belfast BT7 1NN, UK. ${ }^{2}$ Institute for Global Food Security (Centre for Public Health), Grosvenor Road, Belfast BT12 6BJ, UK.

Received: 6 June 2019 Accepted: 13 April 2020

Published online: 22 May 2020

\section{References}

1. World Health Organisation. What is overweight and obesity? [Internet]. 2018 [cited 2018 Feb 12]. Available from: http://www.who.int/dietphysicalactivity/ childhood what/en/.

2. World Health Organization. Obesity and Overweight [Internet]. October 2017. 2017 [cited 2018 Aug 13]. Available from: http://www.who.int/ mediacentre/factsheets/fs311/en/.

3. Risk NCD, Collaboration F. Articles Worldwide trends in body-mass index, underweight, overweight, and obesity from 1975 to 2016: a pooled analysis of 2416 population-based measurement studies in $128 \cdot 9$ million children, adolescents, and adults. 2017:2627-42.

4. Fryar CD, Carroll MD, Ogden CL. Prevalence of Overweight and Obesity Among Children and Adolescents: United States, 1963-1965 Through 20112012 [Internet]. National Center for Health Statistics. 2014 [cited 2018 Aug 27]. Available from: http://www.cdc.gov/nchs/data/hestat/obesity_ child_11_12/obesity_child_11_12.pdf.

5. Centers for Disease Control and Prevention. Physical Activity | CDC [Internet]. 2015 [cited 2018 Aug 27]. Available from: https://www.cdc.gov/ physicalactivity/basics/glossary/index.htm.

6. Lee YS. Consequences of childhood obesity [Internet]. Vol. 38, Annals of the Academy of Medicine Singapore. 2009 [cited 2018 Aug 13]. Available from: http://www.annals.edu.sg/pdf/38VolNo1Jan2009/N38N1p75.pdf.

7. Tang-Péronard $\mathrm{JL}$, Heitmann BL. Stigmatization of obese children and adolescents, the importance of gender. Obes Rev [Internet]. 2008:9(6):52234. [cited 2018 Aug 13]. Available from: http://www.ncbi.nlm.nih.gov/ pubmed/18643945.

8. Ofcome. Children and Parents: Media Use and Attitudes Report [Internet]. 2014 [cited 2018 Aug 13]. Available from: http://stakeholders.ofcom.org.uk/ binaries/research/media-literacy/media-use-attitudes-14/Childrens_2014_ Report.pdf.

9. Jones M, Luce KH, Osborne MI, Taylor K, Cunning D, Doyle AC, et al. Randomized, controlled trial of an internet-facilitated intervention for reducing binge eating and overweight in adolescents. Pediatrics [Internet] 2008;121(3):453-62. Available from: http://ovidsp.ovid.com/ovidweb.cgi?T= JS\&PAGE $=$ reference\&D $=$ med6\&NEWS $=\mathrm{N} \& A N=18310192$

10. Slater A, Tiggemann M. "Uncool to do sport": A focus group study of adolescent girls' reasons for withdrawing from physical activity. Psycho Sport Exerc [Internet]. 2010;11(6):619-26. [cited 2018 Aug 14]. Available from: https://www.sciencedirect.com/science/article/pii/S1469029210000956.

11. Whittemore R, Jeon S, Grey M. An Internet Obesity Prevention Program for Adolescents) 439e447. J Adolesc Heal [Internet]. 2013;52. [cited 2018 Aug 14]. Available from: www.jahonline.orghttp://dx.doi.org/10.1016/j. jadohealth.2012.07.014.

12. Woolford SJ, Clark SJ, Strecher VJ, Resnicow K. Tailored mobile phone text messages as an adjunct to obesity treatment for adolescents. J Telemed 
Telecare [Internet]. 2010;16(8):458-61. [cited 2018 Aug 14]. Available from: http://www.ncbi.nlm.nih.gov/pubmed/20959393.

13. Christison A, Khan HA. Exergaming for Health. Clin Pediatr (Phila) [Internet] 2012;51(4):382-8. [cited 2018 Aug 14]. Available from: http://www.ncbi.nlm. nih.gov/pubmed/22157430

14. An J-Y, Hayman LL, Park Y-S, Dusaj TK, Ayres CG. Web-Based Weight Management Programs for Children and Adolescents. Adv Nurs Sci [Internet]. 2009;32(3):222-40. [cited 2018 Aug 14]. Available from: http:// content.wkhealth.com/linkback/openurl?sid=WKPTLP:landingpage\&an= 00012272-200907000-00005.

15. Daley AJ, Copeland RJ, Wright NP, Roalfe A, Wales JKH. Exercise Therapy as a Treatment for Psychopathologic Conditions in Obese and Morbidly Obese Adolescents: A Randomized, Controlled Trial. Pediatrics [Internet]. 2006; 118(5):2126-34. [cited 2018 Aug 14]. Available from: http://pediatrics. aappublications.org/cgi/doi/10.1542/peds.2006-1285.

16. Trost SG, Sundal D, Foster GD, Lent MR, Vojta D. Effects of a pediatric weight management program with and without active video games a randomized trial. JAMA Pediatr [Internet]. 2014;168(5):407-13. Available from: http://ovidsp.ovid.com/ovidweb.cgi?T=JS\&PAGE=reference\&D= med8\&NEWS=N\&AN=24589566

17. Chen J-L, Wilkosz ME. Efficacy of technology-based interventions for obesity prevention in adolescents: a systematic review. Adolesc Health Med Ther [Internet]. 2014;159. Available from: http://www.dovepress.com/efficacy-oftechnology-based-interventions-for-obesity-prevention-in-a-peer-reviewedarticle-AHMT.

18. Moher D, Liberati A, Tetzlaff J, Altman DG, Altman D, Antes G, et al. Preferred reporting items for systematic reviews and meta-analyses: The PRISMA statement. PLoS Med [Internet]. 2009;6(7):e1000097. [cited 2018 Aug 14].. Available from: http://dx.plos.org/10.1371/journal.pmed.1000097.

19. World Health Organisation. BMI-for-age (5-19 years) [Internet]. WHO. World Health Organization; 2015 [cited 2018 Aug 12]. Available from: http://www. who.int/growthref/who2007_bmi_for_age/en/.

20. Harvard T.H. Chan. School Obesity Prevention Recommendations: Complete List | Obesity Prevention Source | Harvard T.H. Chan School of Public Health [Internet]. [cited 2018 Aug 12]. Available from: https://www.hsph.harvard. edu/obesity-prevention-source/obesity-definition/defining-childhoodobesity/\#definitions.

21. Cole TJ, Lobstein T. Extended international (IOTF) body mass index cut-offs for thinness, overweight and obesity. Pediatr Obes [Internet]. 2012;7(4):28494. [cited 2018 Aug 13]. Available from: http://doi.wiley.com/10.1111/j.204 7-6310.2012.00064.x

22. Cochrane Collabration. Cochrane risk of bias tool (modified) for quality assessment of randomized controlled trials. Cochrane Handb Syst Rev Interv [Internet]. 2011;9-14. Available from: www.handbook.cochrane.org.

23. Williamson DA, Walden HM, White MA, York-Crowe E, Newton RL, Alfonso A, et al. Two-year internet-based randomized controlled trial for weight loss in African-American girls. Obesity (Silver Spring) [Internet]. 2006;14(7):123143. Available from: http://ovidsp.ovid.com/ovidweb.cgi?T=JS\&PAGE= reference \&D=med5\&NEWS $=$ N\&AN $=16899804$

24. AE Staiano, AM Marker, R A Beyl, DS Hsia, PT Katzmarzyk, Staiano AE, et al. A randomized controlled trial of dance exergaming for exercise training in overweight and obese adolescent girls. Pediatr Obes [Internet]. 2017;12(2): 120-8. Available from: http://ovidsp.ovid.com/ovidweb.cgi?T=JS\&PAGE= reference\&D=medc\&NEWS=N\&AN=26918815.

25. Ezendam NPM, Brug J, Oenema A. Evaluation of the Web-based computertailored FATaintPHAT intervention to promote energy balance among adolescents: results from a school cluster randomized trial. Arch Pediatr Adolesc Med [Internet]. 2012;166(3):248-55. Available from: http://ovidsp. ovid.com/ovidweb.cgi?T=JS\&PAGE=reference\&D=med7\&NEWS=N\&AN=22 064878

26. Azmawati Mohammed Nawi. Effect of internet-based intervention on obesity among adolescents in Kuala Lumpur: A school-based cluster randomised trial. Malaysian J Med Sci [Internet]. 2015;22(4):47-56. Available from: http://journal.usm.my/journal/7OA5mjms224.pdf.

27. Chen J-L, Weiss S, Heyman MB, Cooper B, Lustig RH, Jyu-Lin Chen, et al. The efficacy of the web-based childhood obesity prevention program in Chinese American adolescents (Web ABC study). J Adolesc Heal [Internet]. 2011;49(2):148-54. Available from: http://ovidsp.ovid.com/ovidweb.cgi?T= JS\&PAGE=reference\&D=emed13\&NEWS=N\&AN=51316101.

28. Wagener TL, Fedele DA, Mignogna MR, Hester CN, Gillaspy SR. Psychological effects of dance-based group exergaming in obese adolescents. Pediatr
Obes [lnternet]. 2012;7(5):e68-74. Available from: http://ovidsp.ovid.com/ ovidweb.cgi? $=$ TS\&PAGE=reference\&D=med7\&NEWS=N\&AN=22767495.

29. B Nguyen, V A Shrewsbury, J O'Connor, K S Steinbeck, A J Hill, S Shah, et al. Two-year outcomes of an adjunctive telephone coaching and electronic contact intervention for adolescent weight-loss maintenance: The Loozit randomized controlled trial. Int J Obes [Internet]. 2013;37(3):468-72. Available from: http://ovidsp.ovid.com/ovidweb.cgi?T=JS\&PAGE= reference\&D=emed15\&NEWS=N\&AN=52012300.

30. Maddison R, Foley L, Ni Mhurchu C, Jiang Y, Jull A, Prapavessis H, et al. Effects of active video games on body composition: a randomized controlled trial. Am J Clin Nutr [Internet]. 2011;94(1):156-63. Available from: http://ovidsp.ovid.com/ovidweb.cgi?T=JS\&PAGE=reference\&D= med7\&NEWS=N\&AN=21562081.

31. Adamo KB, Rutherford JA, Goldfield GS. Effects of interactive video game cycling on overweight and obese adolescent health. Appl Physiol Nutr Metab [Internet]. 2010;35(6):805-15. Available from: http://ovidsp.ovid.com/ ovidweb.cgi? T=JS\&PAGE=reference\&D=med6\&NEWS $=$ N\&AN $=21164552$.

32. Chen J-L, Wilkosz ME. Efficacy of technology-based interventions for obesity prevention in adolescents: a systematic review. Adolesc Health Med Ther [Internet]. 2014;159. [cited 2018 Aug 27]. Available from: http://www. dovepress.com/efficacy-of-technology-based-interventions-for-obesityprevention-in-a-peer-reviewed-article-AHMT.

\section{Publisher's Note}

Springer Nature remains neutral with regard to jurisdictional claims in published maps and institutional affiliations.
Ready to submit your research? Choose BMC and benefit from:

- fast, convenient online submission

- thorough peer review by experienced researchers in your field

- rapid publication on acceptance

- support for research data, including large and complex data types

- gold Open Access which fosters wider collaboration and increased citations

- maximum visibility for your research: over $100 \mathrm{M}$ website views per year

At BMC, research is always in progress.

Learn more biomedcentral.com/submissions 